\title{
O DESCONFORTO DOCENTE COM A IMPOSIÇÃO PARA ATUAÇÃO NA EDUCAÇÃO A DISTÂNCIA E AS ESTRATÉGIAS PARA SUA SUPERAÇÃO
}

\author{
The discomfort with the imposition to teach in distance learning and the \\ strategies for its overcoming
}

\author{
SILVA, Edson Moura da ${ }^{1}$ \\ MARINHO, Simão Pedro P. ${ }^{2}$
}

\begin{abstract}
Resumo
O mercantilismo na educação se desponta como um nicho de mercado promissor e passa a ser alimentado pela EaD. Com a proliferação da EaD no ensino superior brasileiro, o professor, comumente contratado para atuar em aulas presencias, vê-se obrigado a ministrar disciplinas on-line. Além de constatar a precarização de seu trabalho, no contexto das pressões normativas o professor sofre desconforto e desprazer, tendo que adotar mecanismos de defesa psicológicos como forma de sua superação. $O$ artigo descreve achados de uma pesquisa descritiva e qualitativa realizada junto a docentes que se viram obrigados a atuar na $\mathrm{EaD}$. Os dados foram coletados através de entrevistas semiestruturadas aplicadas realizadas com professores da educação superior que, no período de 2010 a 2017, por imposição institucional assumiram a responsabilidade por disciplinas oferecidas à distância. Foi possível constatar diferentes insatisfações, desconfortos e queixas de mal-estar e identificar diferentes tipos de mecanismos de defesa adotados como forma de superação frente às pressões normativas. Os constructos teóricos acerca dos mecanismos de defesa foram pautados nas teorias psicanalíticas postuladas por Sigmund Freud.
\end{abstract}

Palavras-chave: Educação a Distância. Precarização de trabalho docente. Mecanismos de defesa.

\begin{abstract}
Mercantilism in education emerges as a promising market niche and is fed by the distance education. With the proliferation of distance education in Brazilian higher education, the professor, often hired to attend presences classes, is forced to teach online subjects. In addition to realizing the precariousness of his work, in the context of normative pressures the professor suffers discomfort and displeasure, having to adopt psychological defense mechanisms as a way of overcoming them. The article describes the findings of a descriptive and qualitative research carried out with professors who were forced to work in the EaD. Data were collected through semi-structured interviews conducted with higher education professors who, in the period from 2010 to 2017, by institutional imposition assumed responsibility for disciplines offered at a distance. It was possible to verify different dissatisfactions, discomforts and complaints of malaise and identified different types of defense mechanisms adopted as a way of overcoming the normative pressures. The theoretical constructs about the defense mechanisms were based on the psychoanalytic theories postulated by Sigmund Freud.
\end{abstract}

Keywords: Distance education. Teachers work precarization. Defense mechanisms.

\footnotetext{
${ }^{1}$ Doutor em Educação pela PUC Minas, Mestre em Administração pela Fundação Pedro Leopoldo, Graduado em Psicologia pela Newton Paiva. Professor titular da Faminas BH, Coordenador Pós-Graduação Senac Minas, Colaborador INEP/MEC como avaliador institucional. E-mail: <edsonms@uai.com.brs.

${ }^{2}$ Doutor em Educação pela PUC/SP, Professor titular da PUC Minas, Coordenador do Programa de Pós-graduação em Educação, Presidente da Câmara de Ensino Superior do Conselho Estadual de Educação de Minas Gerais, Membro do Conselho de Educação e Treinamento da FIEMG. E-mail: <marinhos@uol.com.br>.
}

Trabalho \& Educação | v.28 | n.1 | p.169-185 | jan-abr | 2019 


\section{INTRODUÇÃO}

A história da Educação a Distância $(\mathrm{EaD})$ no Brasil remonta a tempos idos, cujo início, por meio do ensino via correspondência, deu-se no período anterior aos anos de 1900, com a oferta de cursos oferecidos por meio de jornais, veiculados no estado do Rio de Janeiro. Mais recentemente, com o advento de novas tecnologias digitais de informação e de comunicação (TDIC), diversas instituições de ensino superior (IES) começaram a utilizar a EaD como alternativa de ensino e de aprendizagem, seja na oferta de disciplinas on-line em cursos ditos presenciais, seja na oferta de cursos de graduação inteiramente à distância.

Por outro lado, a educação on-line (EoL) oferece uma oportunidade inédita de ampliação de oferta de vagas na educação superior. Sob o discurso de democratização de acesso, IES privadas passaram a oferecer mais e mais vagas em cursos de graduação, considerando, sem dúvida, uma realidade de redução de custos que pode implicar em redução de mensalidades para os estudantes. Num quadro de mudanças drásticas do FIES, no momento em que o país passa por uma profunda crise econômica, a redução do número de matriculados em cursos superiores sofre severa redução e diversas IES, especialmente as mantidas pelos grandes conglomerados educacionais, buscam assegurar sua continuidade, oferecendo alternativas, em particular através da EaD.

O ambiente virtual cria um espaço para novas oportunidades de aprendizado, inclusive as de ordem financeira, outrora não experienciadas pelas IES, com a redução expressiva dos seus custos, já que uma menor infraestrutura física é requerida e as despesas fixas de manutenção são muito menores do que em IES "de tijolos". A redução de custos contribui para o aumento de receitas, na maximização da taxa de ocupação da sala de aula virtual, onde o número de alunos supera àquele do modelo tradicional entre quatro paredes. Afinal, a sala de aula de bits não tem paredes limitadoras, nela sempre cabe mais um.

Neste (novo) contexto de EaD, integrantes do corpo docente das IES, até então formados e preparados para lecionar aulas na forma presencial, por vezes se veem obrigados a ministrar disciplinas cujas aulas passam a ser ofertadas em EaD, muito frequentemente na forma semipresencial. Muitas vezes sem receber a devida qualificação e formação para exercer as atividades de docência na EaD, sendo apenas informado sobre a existência do Ambiente Virtual de Aprendizagem (AVA), utilizado para o repositório e busca do material didático, ou no máximo, recebendo um ligeiro treinamento para atuar na nova ambiência, o docente se vê às voltas com novos problemas. Ainda que despreparado para a docência virtual, desconhecendo uma didática para a EaD (PETERS, 2006), o professor se vê obrigado a encarar o (novo) desafio e o AVA culmina por ganhar mais um parceiro, responsável por levar mais um livro ou uma apostila para uma "estante virtual".

No crescimento vertiginoso das "escolas sem tijolos", aos professores contratados com uma determinada carga horária semanal para o exercício das suas atividades profissionais na modalidade presencial são imputadas disciplinas em EoL, em processos não raramente acompanhados do discurso institucional de se evitar a redução de carga horária docente. Isto acontece em um cenário no qual a educação superior no Brasil sofre uma retração, ainda que na circunstância de disciplinas semipresenciais este processo seja inevitável e, inclusive por isto, conveniente nas IES privadas. $O$ vínculo do docente, que tem que substituir as horas/aulas presenciais por 
hora/aula em EaD, é compulsoriamente alterado. Favorecidos pela redução de custos, os lucros das IES continuam aumentando em detrimento do aumento do volume de trabalho docente, ocasionando expressiva redução salarial, aumento da precarização do trabalho e os consequentes mal-estar e adoecimento docente. Na imposição do novo, as IES trazem novos problemas para a vida cotidiana no trabalho dos docentes.

\section{O TRABALHO}

Etimologicamente, a palavra trabalho tem sua origem em duas bases do latim: tripalium, um instrumento de tortura, que remete à associação de fardo e sacrifício, e labor, que significa sofrimento, esforço, dor.

As tradições grega e judaico-cristã entendiam o trabalho como uma atividade penosa e obrigatória, compreendida inclusive como um castigo para o ser humano, tendo uma conotação negativa que representa punição, castigo ou um peso para quem o realiza (GODELIER, 1986).

O significado do trabalho se constrói de forma individual e socialmente. Esses fatores originam as dificuldades para a sua conceituação, porque há de se levar em consideração não somente as formas de percepção, mas, também, como tentar compreender a própria complexidade de cada uma delas, já que existe uma gama de fatores condicionantes e particulares a cada indivíduo (ROSSO; DEKAS; WRZESNIEWSKI, 2010).

Para Marx (1985), o trabalho primeiramente se dá por meio de um processo de ação do homem, que coloca em movimento suas forças a fim de se apropriar dos recursos da natureza numa forma utilizável para a sua própria vida, o que culmina em transformar simultaneamente a própria natureza do homem. Assim, o trabalho é o fio condutor das ações e relações estabelecidas entre os sujeitos e o ambiente em que estão inseridos. Tais relações, segundo Marx (1996), sofreram modificações ao longo da transformação das sociedades e dos homens, chegando à forma de sociedade atual que, a partir da égide capitalista e da supremacia do capital, invoca novas concepções entre os homens e a natureza.

Segundo Frigotto (2010), o trabalho, no capitalismo, se apresenta como uma forma de emprego, na dominação e exploração do homem sobre o homem, no processo mercantil onde ocorre a compra e venda da força de trabalho. $O$ trabalho se faz necessário à existência e à subsistência na vida do homem. Contudo, traz em seu bojo consequências na vida do trabalhador, que pode ser afetada por patologias inerentes a atividades laborais ou implicações psicológicas.

\section{O TRABALHO DOCENTE}

Para Veiga (2012), docência, no sentido etimológico, tem suas raízes no latim docere, que significa ensinar, instruir, mostrar, indicar, dar a entender. A autora afirma ainda que o registro do termo na língua portuguesa é datado de 1916, o que implica dizer que a utilização e a apropriação do termo é algo relativamente recente no espaço dos discursos da educação. Em um sentido mais amplo, entende-se por profissão toda atividade, ocupação, função ou emprego que é a fonte principal dos meios de vida de alguém (MONTEIRO, 2015). 
O caráter de fé e sacerdócio no exercício da profissão docente foi discutido por diferentes autores. Nas palavras de Freire (1996, p. 161), a vocação é uma força misteriosa "que explica a quase devoção com que a grande maioria do magistério nele permanece, apesar da imoralidade dos salários" e que acaba por cumprir o seu dever como pode.

Tardif e Lessard $(2005$, p.9) entendem a docência como uma "forma particular de trabalho sobre o humano, ou seja, uma atividade em que o trabalhador se dedica ao seu 'objeto' de trabalho, que é justamente um outro ser humano, no modo fundamental de interação humana". Os autores propõem uma perspectiva transformadora do contexto social por meio do trabalho docente, como sendo uma atividade cognitiva e interativa que se constitui como uma das formas para se compreender as mudanças no mundo do trabalho (TARDIF; LESSARD, 2005).

A precarização do trabalho docente, fenômeno que com certeza não é novo (BOSI, 2007), impetra uma pressão silenciosa, um controle que aflora paulatinamente como pressão e manifestação de ideias de comiseração no corpo docente, gerando a necessidade pela busca incessante de formação continuada. A precarização do trabalho se faz presente tanto na excessiva carga horária de atividades compulsórias, quanto no elevado número de alunos em sala de aula ou na alta rotatividade, como na alternância dos vínculos empregatícios dos professores e na inexistência de um plano de carreira (SOUSA, 2013). O preocupante é que são situações que podem ser agravadas na realidade posta pela recente reforma trabalhista, com a terceirização da função primária e o trabalho intermitente, por exemplo.

Assim, a precarização do trabalho docente repercute sobre a construção da identidade dos professores, compreendendo-a como uma construção histórico-social que perpassa o processo de socialização (ARNOSTI; BENITES; SOUZA NETO, 2013).

\section{A EAD NAS IES BRASILEIRAS}

Educação a Distância ${ }^{3}(E a D)$ não é um conceito novo; remonta a tempos idos, sendo difícil encontrar o marco inicial de sua história. A EaD perpassou os tempos da mídia analógica, com a correspondência, o rádio e a televisão como meios para atingir um número maior de estudantes-espectadores com o advento da internet.

Nos termos do Decreto 2.494, de 10 de fevereiro de 1998, a EaD é a

forma de ensino que possibilita a autoaprendizagem, como a mediação de recursos didáticos sistematicamente organizados, apresentados em diferentes suportes de informação, utilizados isoladamente ou combinados, e veiculados pelos diversos meios de comunicação.

Com o desenvolvimento das tecnologias digitais, notadamente a internet, a EaD vai encontrar no AVA um novo espaço para a ampliação de sua oferta. O AVA, que engloba várias tecnologias simultaneamente, propicia a difusão, a compreensão e o desenvolvimento do conhecimento e o acesso sincrônico e assíncrono aos diversos documentos e materiais instrucionais que estão postados. No AVA, o aluno é capaz de interagir e cooperar com diferentes sujeitos, contextos e objetos de conhecimento, e

\footnotetext{
${ }^{3}$ Para alguns autores, não pode haver educação a distância, mas ensino a distância. A justificativa está no fato de que a educação, da mesma forma que a aprendizagem, é processo que ocorre dentro do indivíduo. Assim, não seria possível a alguém educar outro a distância, mas apenas ensinar-lhe.
} 
ambientes que abarcam diferentes ferramentas, que podem ser utilizadas pelos agentes envolvidos, tais como e-mail, fórum, chat e lista de discussão.

Especialmente a partir do surgimento e do desenvolvimento da internet, o ensino a distância vem se concretizando nas instituições de ensino superior (IES) em todo o mundo, ainda que com diferentes modelos pedagógicos, institucionais e tecnológicos. Todavia, o desenvolvimento cada vez mais acelerado das TDIC tende a influenciar também o ritmo de mudança, adaptabilidade e utilização nas instituições de ensino, e não só da educação superior ${ }^{4}$.

Por outro lado, Neves e Fidalgo (2008) fazem alusão às estratégias utilizadas pelas IES para precarização do trabalho docente, decorrentes da utilização das novas tecnologias tanto para promover a dispersão da mão-de-obra, como consequente aumento da carga de trabalho docente que se mantém empregado. Assim, os autores resgatam os pressupostos de mais-valia", apregoados por Karl Marx, ao afirmarem que "o trabalho docente na $\mathrm{EaD}$, que tem suas atividades mediadas pelas tecnologias digitais, tem sido tomado num contexto de exploração [...] pelo capital no âmbito educacional" (NEVES; FIDALGO, 2008, p. 4).

Ao que parece, a hora/aula perpetrada pela parede de tijolos agora se realiza em uma tela de computador ou de um dispositivo móvel. Na EoL, o professor não cumpre mais apenas a jornada marcada por horas-aula em um determinado horário em um local específico, mas a extrapola, seja por ter que cumprir com os prazos estipulados pelas IES, muitas vezes de 48 ou 72 horas de resposta ao aluno, seja no excesso de tempo despendido para correção, comentários e postagem das atividades avaliativas, sem contar o enorme tempo despendido no atendimento aos estudantes, em um modelo de atendimento que acaba se tornando individualizado. Como em substituição ao parâmetro hora-aula, que regula o horário de trabalho e é referência para o pagamento pelo serviço prestado, não se estabeleceu um novo parâmetro, "hora/bit", e a exploração do trabalho docente se amplia. Karl Marx talvez concordasse com o fato de que, agora, a mais valia se revela de forma 'exacerbada' na EaD, desnudando em um novo formato de apropriação dos auferes, uma vez que se pagam menos horas para um 'operário da educação' que trabalha muito além das horas contratadas, o que não se traduz em e nem tampouco assegura a qualidade dos serviços prestados.

Durante mais de oito décadas de história da EaD no Brasil, os investimentos nessa modalidade de ensino, quase em sua totalidade, foram concebidos por iniciativa pública, havendo pouca ou nenhuma iniciativa por parte das IES privadas, cenário que se desponta de forma invertida a partir do início do século XXI (MUGNOL, 2009). A partir do ano de 2005, momento em que se inicia um crescimento vertiginoso das IES privadas, favorecido especialmente pela elevação considerável do número de novos contratos do Fundo de Financiamento Estudantil (FIES) ${ }^{6}$, é que se dá também o início do processo, ainda que embrionário, de difusão do ensino em EaD por meio das IES

\footnotetext{
${ }^{4}$ A possibilidade da oferta de EaD no ensino médio, trazida pela Reforma do Ensino Médio posta pela Lei 13.415/2017b, de alguma forma assusta educadores e vem sendo mote para acaloradas discussões, especialmente no momento em que se discute a proposta da BNCC para este segmento da educação básica.

${ }^{5}$ A mais valia absoluta, postulada por Karl Marx, é aquela na qual os capitalistas utilizam uma quantidade de horas excedentes ao necessário para pagar ao trabalhador um salário pelo uso da força de trabalho cotidiano, utilizando e se apropriando de todo o trabalho, mantendo o salário constante.(MARX, 1985, p. 60-62).

${ }^{6}$ Em 2010 foram celebrados 78 mil novos contratos; em 2014 o número atingiu surpreendentes 733 mil, fazendo com que o Programa se transformasse em fonte garantida de renda para as IES privadas. De um total de beneficiados em torno de 200 mil entre 2002 e 2010 , chegou-se a algo em tomo de 2 milhões por volta de 2014. Com um rombo potencial identificado, pelo aumento do número de calotes, o número de novos contratos começa a sofrer uma queda em 2015.
} 
particulares de ensino, de forma massificada, não raro preterindo-se a qualidade em prol da quantidade de alunos matriculados.

Com oferta prevista na Lei 9.394/96 (BRASIL, 1996), mais exatamente no seu art. 80, a EaD foi regulamentada através do Decreto 5.622 (BRASIL, 2005), que recentemente foi revogado pelo Decreto 9.235 (BRASIL, 2017b). Com a nova regulamentação, as IES já podem oferecer cursos exclusivamente à distância, desfazendo-se a exigência anterior da oferta simultânea de cursos presenciais. O argumento do MEC para permitir esta nova situação é o da necessidade de ampliar a oferta do ensino superior no país para que seja possível cumprir a Meta 12 do Plano Nacional de Educação (PNE) (BRASIL. MEC, 2016). Pela referida Meta, as taxas bruta e líquida de matrícula na educação superior devem ser aumentadas, respectivamente, para 50\% e 33\% da população de 18 a 24 anos. Evidentemente que essa liberação favorece o surgimento e ampliação da oferta da EaD na educação superior por instituições privadas. Não se pode negar que há, por parte do atual Governo Federal, um movimento no sentido da ampliação da mercantilização do ensino.

Tanto é que a ampliação da mercantilização vai atingir outras modalidades da Educação. O Decreto 9.235 (BRASIL, 2017b) regula ainda a oferta de cursos a distância para o ensino médio e para a educação profissional técnica de nível médio, com o alegado propósito de atender ao Novo Ensino Médio, conforme definido pela Lei 13.415/2017 (BRASIL, 2017a). Nos termos desta Lei, no Parágrafo 11 do art. 36 da Lei 9.394/96, prevê-se que "para efeito de cumprimento das exigências curriculares do ensino médio, os sistemas de ensino poderão reconhecer competências e firmar convênios com instituições de EaD com notório reconhecimento". Sem dúvida, cria-se um campo potencialmente enorme para os grandes conglomerados de educação, que já buscam produzir e oferecer às escolas com ensino médio pacotes educacionais que passam a incluir vídeo-aulas. No momento em que as escolas se debatem na busca de soluções para a oferta dos itinerários formativos do ensino médio, a oferta dos pacotes, favorecida ainda pelo disposto no Inciso IV do art. 61, em sua nova redação dada pela Lei 13.415/2017, permite que profissionais com notório saber, reconhecido pelos respectivos sistemas de ensino, possam atuar no ensino médio ministrando conteúdos de áreas afins à sua formação ou experiência. Essa estratégia permite atender-se 0 disposto no Inciso $V$ do caput do art. 36, que trata da formação técnica e profissional.

É todo um prenúncio da materialização dos sonhos fordianos. Tais ideias encontram consonância com a perspectiva de Lessa (2011, p.20): "É neste cenário que se deve enxergar a legislação que regulamenta essa modalidade como fundamental para a quebra do paradigma da qualidade e da estigmatização que tem dominado a história da educação durante anos".

A expansão da posse de dispositivos de tecnologia digital e a ampliação do acesso à internet coincidem quando se destaca a necessidade de ampliação do número de estudantes na educação superior, conforme posto pela Meta 12 do Plano Nacional de Educação (BRASIL. MEC, 2016) ${ }^{7}$. É nesse contexto que a EaD vem se ampliando nos últimos anos como estratégia para ampliação da oportunidade de acesso à educação superior. De acordo com o Censo da Educação Superior de 2015 do Ministério da Educação (MEC), dos pouco mais de 8 milhões de estudantes, quase 1,4 milhão

\footnotetext{
${ }^{7}$ Meta 12: Elevar a taxa bruta de matrícula na educação superior para 50\% (cinquenta por cento) e a taxa líquida para 33\% (trinta e três por cento) da população de 18 (dezoito) a 24 (vinte e quatro) anos, assegurada a qualidade da oferta e expansão para, pelo menos, 40\% (quarenta por cento) das novas matrículas, no segmento público.
} 
cursavam cursos à distância. Se considerarmos que em 2005 eram cerca de aproximadamente 100 mil os alunos matriculados na EAD em todo o país, o número constatado em 2015 revela um crescimento da modalidade de mais de $1.000 \% \mathrm{em}$ apenas 10 anos.

Dessa forma, muitas IES privadas viram e veem na EaD a possibilidade de conjugar seus interesses mercantis com a Meta 12 do PNE. Assim, adotam o discurso de que será através da EaD que se potencializará o acesso à educação superior, inclusive através da redução dos custos que cabem aos estudantes. Manter salas virtuais, de bits, representa custo bem menor quando comparado com as salas de tijolos, pois não há gastos com energia elétrica, limpeza, manutenção de instalações sanitárias e até mesmo os encargos que cabem aos imóveis (IPTU, alvará de localização e outros). Na sala "ilimitada" de bits, o número de estudantes extrapolará em muito o daqueles que, assentados em carteiras enfileiradas, assistem aulas na sala de tijolos. Na educação presencial é necessário um professor para atender 50, 60 estudantes na sala de tijolos, na sala de bits esse mesmo professor atenderá 200, 300 ou mais estudantes, em situação de precarização do seu trabalho. Massifica-se a educação para ofertá-la a preços acessíveis. Pretensamente, barateia-se a educação superior. Entretanto, nesse cenário aparentemente auspicioso de democratização de acesso, de repente poderemos estar fazendo uma escola pobre para pobres.

\section{Percurso na inVestigação}

O ponto de partida dessa pesquisa foi a Portaria $n^{\circ} 4.059 / 2004^{8}$, que autorizava as IES a destinarem até $20 \%$ da carga horária total de cursos de graduação reconhecidos pelo Ministério da Educação (MEC) na oferta de disciplinas em EaD.

Com a publicação da Portaria 4.059, não foram poucas as IES que prontamente caminharam na perspectiva de oferecer disciplinas integrantes dos seus currículos que

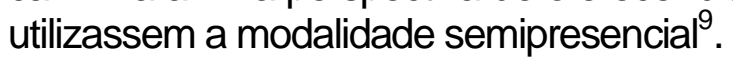

Na realidade constatada da docência na sala de aula virtual como consequência de imposição institucional, com a presente pesquisa buscamos resposta para a pergunta: "Para a superação de um eventual desconforto pela atuação compulsória na EaD, quais estratégias são utilizadas pelos docentes"?

Para facilitar o alcance do objetivo geral da pesquisa, buscamos identificar junto a docentes que se viram na circunstância de atuar na EaD por imposição institucional: (a) impactos decorrentes da pressão normativa; (b) sentimentos que suscitam desconforto e desprazer na atuação na EaD; (c) motivos que contribuem para a sua permanência na EaD; e (d) as diferentes formas de superação do desconforto que possam adotar.

Os procedimentos metodológicos e técnicas de investigação adotados no presente estudo foram, em estudo de casos múltiplos, a pesquisa descritiva e qualitativa.

\footnotetext{
${ }^{8}$ Ao longo do desenvolvimento da pesquisa, a Portaria 4.059/ foi substituída pela Portaria MEC 1.134, de 10 de outubro de 2016, que deu uma nova redação para a questão.

${ }^{9}$ A Portaria 4.059 , em seu art. 1ํ, falava em oferta na modalidade semipresencial. O prefixo "semi" pressupõe que metade da carga horária da disciplina se daria em atividades presenciais e as demais à distância. Neste caso, não seria possível a oferta de disciplina integralmente à distância, ainda que esta tenha sido a prática adotada em muitas IES. Possivelmente para permitir esta situação, observando-se ainda o limite de $20 \%$ da carga horária total do curso para a oferta das disciplinas em EaD, a Portaria 1.134/2016, que substituiu a Portaria 4059/2004, alterou a redação para "modalidade a distância".
} 
No estudo de casos múltiplos o pesquisador descreve mais de um sujeito em seus estudos (STAKE, 2006; YIN, 2005). Os benefícios advindos da utilização de casos múltiplos podem ser substanciais, "independentemente de qualquer restrição de recursos, se múltiplos candidatos forem qualificados para servir como casos, quanto maior o número que você puder estudar, melhor" (YIN, 2005, p. 118).

A pesquisa descritiva expõe, ainda, as características de determinada população ou determinado fenômeno, no intuito de descrever os acontecimentos. Contudo, não tem o compromisso de explicar os fenômenos que descreve, embora sirva de base para tal explicação (VERGARA, 2014).

Os estudos qualitativos buscam descrever a complexidade de determinado problema, bem como a reciprocidade entre certas variáveis, na compreensão e no entendimento das particularidades acerca do problema investigado e contribuindo para uma análise mais detalhada dos fenômenos investigados (MARCONI e LAKATOS, 2016).

A ação do pesquisador deve estar voltada para focalizar processos, significados e compreensões, sendo resultado da pesquisa, com apontamentos detalhados na apropriação do fenômeno social observado, "na compreensão dos agentes, daquilo que os levou singularmente a agir como agiram" (GOLDOI e BALSINI, 2006, p. 91).

Foram realizadas entrevistas semiestruturadas para a coleta de dados. A entrevista possibilita uma interação social, no relacionamento entre entrevistador e entrevistado que faz parte ou é afetado pelos fenômenos estudados, levantando dados que permitam uma análise qualitativa, buscando aspectos mais relevantes de um problema de pesquisa (GIL, 2008).

\section{Resultados e Discussão}

Alguns tópicos foram apontados pelos professores e considerados importantes para o processo da pesquisa, uma vez que reforçam o aporte para a condução da pesquisa. São eles:

a) O processo de escolha das disciplinas na modalidade EaD;

b) A designação de docentes para atuação na EaD;

c) Programa de formação docente na EaD adotado pela IES;

d) As condições de trabalho - O trabalho nos trabalhos escolares e nas provas;

e) As pressões normativas e seus impactos no bem-estar docente.

De acordo com as percepções dos docentes, o processo utilizado pela IES para a definição das disciplinas que serão ofertadas na modalidade EaD se dá basicamente pelo número de turmas e de alunos matriculados. Para a designação docente, todos os professores entrevistados afirmaram que foram obrigados a atuarem na EaD como forma de manutenção de sua carga horária contratual anterior, ou como condição preponderante para a sua manutenção do emprego, mesmo que, por vezes, tendo que assumir disciplinas que não eram de sua expertise.

A formação do corpo docente para a atuação na EaD se deu em dois momentos distintos, ambos com o intuito de difundir as ferramentas e os aspectos técnicos do $\mathrm{AVA}^{10}$. Na verdade, o que the foi oferecido era um treinamento do uso do AVA, buscando um domínio mínimo que lhes permitisse atuar na sala de aula virtual. Não se

\footnotetext{
${ }^{10}$ No caso, o AVA utilizado pela IES à qual se vinculam os docentes entrevistados é o Moodle.
} 
pode entender que o treinamento satisfaça uma formação para a docência virtual. Por analogia, seria como ensinar o professor a utilizar o quadro de diz e entender que isto é suficiente como formação para a docência na educação dita presencial.

Um ponto central nas afirmações dos professores é a busca pela ajuda médica em um dado momento que o corpo não suporta mais a pressão e, por vezes, chegando ao seu limite e sucumbido à doença, precisando de auxílio terapêutico para a retomada do bem-estar físico.

Foi possível, nas entrevistas, a identificação de elementos que corroboram a ideia do mercantilismo marcado pela massificação do ensino, quando os professores fazem assertivas correlatas àquelas do discurso dos empresários da educação. Dentro dessa perspectiva mercantilista, Neves e Fidalgo (2008) afirmam que a legislação do sistema educacional brasileiro contribui para a propagação da EaD nas IES, não sendo possível estancar esse crescimento, e dando espaço para o fluxo de mercantilização da educação (BITTAR, 2013). As IES, quando mercantilizadas, atuam como indústrias formadoras de mão-de-obra especializada. Dessa forma, operam como se fossem grandes fábricas de "produção do conhecimento" (RAMOS-DE-OLIVEIRA 1998, p. 2122).

O processo de formação de professores deveria trazer consigo recompensas, como apregoado por Corrêa (2017) que afima "[...] a participação dos professores nos processos formativos deve ocorrer por um processo de adesão, devido a uma motivação intrínseca, e não apenas devido a recursos compensatórios". (CORRÊA, 2017 , p. 117, grifo nosso). Contudo, a adesão dos professores no processo de formação para atuação na EaD, oferecido pela IES em que trabalham ou trabalharam, deu-se de forma compulsória a fim de evitar a 'punição' implícita e velada na forma de demissão. Assim, não existiria, em princípio, um mecanismo compensatório, pois os professores assumem a docência virtual para 'fugir' ao processo de rescisão de contrato de trabalho.

Existe, por trás de um discurso de comodidade pelo trabalho realizado fora do ambiente institucional, uma pseudo-flexibilidade, concernente ao local de trabalho, ao tempo e horário de trabalho, bem como do volume de tarefas e obrigações, reforçando a precarização do trabalho docente em detrimento da majoração da exploração capitalista (MILL; SANTIAGO; VIANA, 2008). No que concerne à quantidade de alunos em uma 'sala de aula' na EaD, resgatam-se as ideias de Marinho e Rezende (2014), que apontam para a possibilidade da existência de muitos alunos na sala de aula virtual devido à inexistência de cadeiras/carteiras como agente limitador do espaço físico. Parece que retornamos ao ditame da profissão docente como sacerdócio, conforme apontado por Alves (2006, p.9), em que se fazia "uma profissão de fé, jurando fidelidade aos princípios da instituição e doação [...] aos alunos independentemente das condições de trabalho e do salário". Ao professor cabe o (des)contentamento.

Quanto à manutenção do estado de saúde física e mental, Falcão e Macedo (2005) afirmam ser necessário que o sujeito seja escutado e articule o que há e habita dentro de si a fim de amenizar os seus sofrimentos. 


\section{As estruturas de personalidade e os MECANISMOS DE DEFESA DA NEUROSE}

Freud (1898) faz menção a uma fase do desenvolvimento psíquico constituinte da estrutura de personalidade do homem, a fase fálica, onde todo ser humano tem para com os seus progenitores sentimento dúbio, de amor e ódio, de desejo e repressão, do ímpeto em fazer o que quer e a imposição das normas e valores. Assim, a criança deverá substituir o progenitor amado por uma pessoa semelhante, que deverá ser encontrada na sociedade, constituindo, assim, a estrutura neurótica.

Com a supremacia desses sentimentos vivenciados e que atribulam a mente humana, na fase fálica existem, basicamente, dois caminhos a serem trilhados, os quais definirão os dois tipos de estrutura da personalidade. A primeira possibilidade, muito embora não hierárquica, mas aqui apresentada apenas com o propósito narrativo, é o da superação de tais conflitos através do recalque que, para Freud (1898), é o mecanismo psíquico do esquecimento e, nas palavras de Bock; Furtado; Teixeira (2011) é o mais radical de todos os mecanismos de defesa utilizado pelo Ego, com o objetivo de afastar da mente humana todo conteúdo que a aflige, suprimindo-o no inconsciente. Dessa maneira, surge a Neurose ${ }^{11}$, uma estrutura de personalidade que se apresenta como solução para a inserção na cultura e na vida social, servindo como fonte geradora dos mecanismos de defesa do Ego.

O outro caminho a ser percorrido é o não registro ou a falta do registro dessa supressão que tortura a psique, dando origem à foraclusão ${ }^{12}$.

Nas neuroses, foco da presente discussão, o docente combate e enfrenta o sofrimento, a angústia e a insatisfação advindos da carga de trabalho elaborando estratégias defensivas como forma de amenizar, disfarçar ou mascarar os sentimentos causadores de mal-estar.

Para Freud (1977), os mecanismos de defesa são uma terminologia utilizada para designar as operações inconscientes que visam a afastar do campo da consciência os conteúdos indesejáveis que geram o desconforto, desprazer, constrangimento e dor. Nenhuma pessoa utiliza todos os mecanismos de defesa existentes. Cada indivíduo utiliza alguns deles, que ficam fixados em seu aparelho psíquico, tornando-se, frequentemente, uma modalidade regular de reação de seu caráter, as quais se repetem quando vivenciadas situações semelhantes àquela primeira. Dentre eles destacam-se: Anulação, Formação Reativa, Formação Substitutiva, Identificação, Isolamento, Negação, Projeção, Racionalização e Regressão (LAPLANCHE; PONTALIS, 1986); (HUFFMAN; VERNOY; VERNOY, 2003); (BOCK; FURTADO; TEIXEIRA, 2004).

\section{OS MECANISMOS DE DEFESA dOS PROFESSORES NA ATUAÇÃo COMPULSÓRIA NA EAD}

A descrição dos diferentes mecanismos de defesa psicológicos, utilizados por entrevistados, como forma de superação, diante das pressões normativas da IES para atuação nas disciplinas EaD, são apresentados a seguir, juntamente com algumas

\footnotetext{
${ }^{11}$ A neurose ou o neurótico, ao contrário do que o senso comum reverbera, é uma estrutura psicológica atribuída a um sujeito 'normal'.

${ }^{12}$ Termo cunhado por Jacques-Marie Émile Lacan (VIGANÒ, 1999).
} 
transcrições correspondentes às suas falas, cujos elementos discursivos encontram correspondência com os mecanismos de defesa avaliados.

Os dados coletados, por meio das entrevistas, foram agrupados a partir das categorias de análise, utilizando a transcrição das considerações apontadas pelos docentes, tal qual foi relatado na entrevista, buscando os elementos discursivos que denotam congruência com as categorias de análise investigadas. Ao preservar a fala de quem fala, demarca-se o caminho da escuta para, assim, estruturar os conceitos que constituem o sujeito (FOCHESATTO, 2011).

As pressões normativas para a atuação docente na EaD acabam gerando diversas queixas, insatisfações e mal-estar psíquico, que foram identificados em todas as entrevistas realizadas com os participantes. Como forma de superação dos desconfortos, os professores acabam adotando os diferentes mecanismos de defesa psicológicos, conforme dados coletados por meio das entrevistas realizadas, dentre eles: Formação Reativa, Isolamento e Projeção.

Indícios da Formação Reativa foram identificados na fala do Professor 4: 'Mas na dinâmica atual da nossa vida ainda vale a pena trabalhar em casa, para poder administrar essa questão de deslocar, tem ainda a pressão do trânsito até a IES, aí vem a questão de EaD que facilita, ajuda". É desta forma que o Professor 4 aponta uma justificativa menos dolorosa para sustentar o discurso de permanência docente na $\mathrm{EaD}$, ainda que isto Ihe traga insatisfação e muita pressão. Opta por desenvolver um trabalho excessivo (ou trabalho excedente?!) em sua casa, que não é (totalmente) remunerado, ancorado em um discurso de evitar a pressão do trânsito. Tais considerações estão correlacionadas com os apontamentos teóricos acerca da formação reativa postulados por Freud (1913). Para o autor, a existência de forças motivadoras, na vida mental do sujeito, ocasiona a substituição de uma ideia pelo seu oposto, em que o sujeito faz uso de sua atividade imaginativa a fim de satisfazer os desejos que na realidade não consegue satisfazer.

O Isolamento foi evidenciado no depoimento do Professor 5. Diante dos principais incômodos causados no processo de ensino na EaD ele afirmou: "Deixe-me pensar um pouco (pausa). Bem, o que mais me incomodava nesse processo todo (pausa) hum... era... ou melhor eram tantas coisas, sabe. Mas a principal, a que mais me desgastava mesmo eram as provas. Nossa. Era muito difícil [...]. Nota-se que o Professor 5 acaba, inconscientemente, recorrendo em seus discursos a uma mesma característica de defesa, suprimindo a sequência da sua fala na apresentação de suas ideias, por meio de pausas e hiatos de pensamento. Em correlação a essas considerações, Laplanche e Pontalis (1986) afirmavam que o isolamento designa "um processo específico de defesa [...] que consiste numa ruptura das conexões associativas de um pensamento ou de uma ação, nomeadamente com o que os precede e os segue no tempo" (LAPLANCHE; PONTALIS, 1986, p. 336).

A Projeção, como mecanismo de defesa, pôde ser detectada quando o Professor 3 alega ter efetuado a sua matrícula em um curso de especialização na modalidade EaD para aprender da mesma forma que os seus alunos aprendiam.

Então eu senti isso, eu comecei a fazer como os alunos faziam, inicialmente. [...] aí eu falei assim: "Não, tem que ser um acompanhamento toda semana. Eu tenho que entrar no sistema, ver o que o professor está postando, tentar tirar alguma dúvida que eu tenho como ele". E aí eu comecei a agir dessa forma e aí realmente eu vi que eu melhorei como aluno. (Professor 3). 
Nota-se que o professor 3, com o intuito de compreender melhor o processo de ensino e de aprendizagem na EaD, matriculou-se em curso nessa modalidade para conhecer a realidade percebida pelos seus alunos, as dificuldades, as pressões de tempo. Para isso adotou comportamentos correlatos aos dos alunos, deixando para realizar as atividades na última hora, avaliando a sua postura e melhorando a sua percepção como aluno. Essas ideias vêm ao encontro dos apontamentos de Costa (2011), que afirma que nesse mecanismo de defesa o sujeito tende "a atribuir a outros as ideias [...] que não consegue admitir como suas” (COSTA, 2011, p. 25).

Cada um dos professores entrevistados disse que tinha, em uma única disciplina, mais de 360 alunos, recebendo apenas duas horas/aula semanais para o exercício das atividades como tutores nos $\mathrm{AVA}^{13}$. Assim, tomando-se como referência uma média de 60 (sessenta) alunos em uma tradicional sala de aula de tijolos, para cada disciplina ofertada na modalidade EaD a IES deixa de contratar outros cinco professores.

E, claro, ainda haverá a redução dos custos indiretos. É a verdadeira proposição do princípio da racionalidade econômica. A mais valia relativa, facilmente percebida nos processos automatizados das indústrias, engendra-se em um novo destino, ela encontra um novo ambiente, que agora é (re)produzido pelas IES, o mercado da educação.

Dentre os fatores detectados, que contribuem para o mal-estar docente frente à imposição para atuação nas disciplinas EaD, destacam-se:

- Elevado número de alunos matriculados nas disciplinas;

- Inconsistência e desatualização do material didático;

- Realização de atividades que exigem pouco conhecimento e habilidade;

- Volume de trabalho e baixa remuneração;

- O excesso de vigilância e o controle institucional exercido no AVA;

- As atividades profissionais não possibilitam o contato e o convívio social com os pares, gestores e alunos;

- O esgotamento físico e mental, que obriga a recorrer ao uso de medicamentos.

Os objetivos da pesquisa foram alcançados. Pudemos identificar nove diferentes tipos de mecanismos de defesa psicológicos adotados pelos cinco professores entrevistados, por conta da imposição para a atuação na EaD, condicionada a ela a permanência do docente na IES. A formação substitutiva e a identificação foram os mecanismos de defesa mais observados entre os entrevistados; a regressão foi a menor constatação.

Ainda que alguns se acostumem à nova realidade, até mesmo em um comportamento darwiniano de adaptação ao meio, na estratégia para a sobrevivência, o desprazer e o desconforto são registrados pelos professores, que lançam mão de diferentes formas de superação do desconforto para que possam atuar na docência a distância.

\footnotetext{
${ }^{13}$ No seu art. $2^{\circ}$, a Portaria MEC 1134/2016 estabelece que as disciplinas de graduação oferecidas em EaD deverão prever atividades de tutoria. Nos termos do Parágrafo único do referido Artigo, a prática da tutoria implica na existência de profissionais da educação com formação na área do curso no qual a disciplina é oferecida em EaD e adequadamente qualificados em nível compatível com o projeto pedagógico do curso. A Portaria não faz referência ao professor da disciplina, embora ele seja um personagem pressuposto, fala-se em tutoria, mas não em docência. No nosso entendimento, que é compartilhado por outros que fazem $\mathrm{EaD}$, o tutor seria um (novo) personagem que se agrega ao processo de formação, apto a oferecer um apoio mais espećíico e individualizado ao estudante durante o seu processo de formação. Para outros, o tutor é o próprio professor na EaD, tutoria se torna sinônimo de docência. No modelo da UAB, do próprio MEC, professor e tutor são personagens distintos; em algumas IES privadas sequer há referência ao professor na EaD, fala-se apenas em tutor. A Portaria MEC 1134/2016 não nos permite inferir quem esteja com razão, quem considera que professor e tutor são personagens diferentes, com papéis distintos, ou se ambos os papéis, docência e tutoria, coincidiram em um mesmo único personagem.
} 
Mesmo com os docentes se esforçando para bem executar o seu trabalho, certamente não se pode esperar muita qualidade de uma ação marcada por tantos incômodos.

\section{CONSIDERAÇÕES FINAIS}

A EaD há muito tem se destacado, em algumas IES de ponta, como um ideal de disseminação do processo de ensino e de aprendizagem, a fim de propiciar aos estudantes, que optam por essa modalidade de ensino, seja por identificação com todo o processo ou pela facilidade remota de acesso, flexibilidade de espaço físico e de horário e assincronismo, dentre outras razões. Reconhecidamente é uma modalidade de ensino que visa incluir um maior número de alunos que necessitam ou que desejam buscar uma qualificação profissional; sua oferta na realidade educacional é inconteste e irreversível. Contudo, outras tantas IES parecem querer apenas ampliar o seu faturamento, com uma substancial redução de seus custos diretos e indiretos, aumentando a sua rentabilidade, muitas vezes em detrimento da manutenção e das garantias da qualidade.

A atuação compulsória na EaD em algumas IES privadas, como a que foi caracterizada na presente pesquisa, traz em seu bojo consequências desastrosas para o corpo do docente. Ter que aceitar uma sala de aula na $\mathrm{EaD}$ com um número excessivo de alunos é o mesmo que perpetrar a senescência, uma degeneração da saúde. O discurso de que o trabalho remoto pode ser realizado no conforto do lar e sem o estresse percebido em uma sala de aula presencial beira o eufemismo. Por um lado, mascara o excesso de tempo despendido com as atividades profissionais; por outro, oculta a maximização dos resultados obtidos e a redução de custos diretos e indiretos advindos com as disciplinas na EaD.

As IES continuam ganhando mais alunos, os profissionais de saúde e as indústrias farmacêuticas mais pacientes e clientes fiéis, os professores. É uma roda sem fim. $O$ teletrabalho, realizado em casa, emergiria como um ganho secundário minimalista, pois se torna melhor trabalhar muito em casa do que trabalhar na IES. Faz-se necessário que a categoria dos professores se organize para discutir, preferencialmente junto ao sindicato de classe, a precariedade do trabalho e os impactos na qualidade de vida trazidos na docência virtual. Enquanto isso, a roda continua girando e os auferes aumentando. É um negócio da China, oferta de produtos baratos, em grande escala. As IES estão com a faca e o queijo na mão, só falta o cafezinho, que, aliás, aos docentes virtuais não mais precisa ser oferecido, reduzindo em mais um ponto o custo dos cursos.

Talvez esteja aí o ponto central de uma possível contribuição da nossa pesquisa para a academia, pelo fato de ser uma conjectura que discorre sobre o item investigado sob a ótica multidisciplinar, que culmina por concluir a evidência de que a imposição para a atuação na EaD, ao mesmo tempo em que é uma violência, uma crueldade impetrada pela ameaça da demissão, culmina em insatisfação, desconforto e desprazer no corpo docente, que acaba adotando diferentes mecanismos de defesa como estratégias de superação.

Com a EaD, as IES agora podem atender em atacado. A produção em massa parece ter chegado inexoravelmente ao mercado educacional, a educação virou uma mercadoria de troca. Basta poder pagar para receber o produto exposto na prateleira. $O$ vale tudo se instaura, para 'abocanhar o maior market share'. Desde a entrada - em 
que o acesso nas IES particulares dispensa os exames vestibulares, substituindo-os, em sua maioria, por uma redação que, em alguns casos, sequer é lida - ao diploma, parecem prevalecer o interesse pela redução de custos, com ampliação dos lucros para alegria dos proprietários das IES ou para dar satisfação aos acionistas. As maneiras de captar e manter estudantes, os clientes, são diversas. Tem a 'feira' com mostra de profissões, a Black Friday, com descontos nos valores devidos, os 'plantões de madrugada para dirimir as suas dúvidas', os 'programas de indicação de colegas e amigos', o financiamento próprio - que facilita a sua [do estudante] vida - e, além de tudo, os slogans, e que 'slogans'

Quão minorativos são os escritores da nossa história, diante de um público inepto e contemplativo. Quão saudável é o circo e quanta carência do pão, que sacia e que mataria a fome eterna. Mas o pão é diminuto e para poucos. Então continuemos com o mercado. Esse é o produto, aqui está o pão; agora que a massa se alimente. Que seja esse o seu circo, que cerceia e o circunda.

Criamos as trilhas, o discurso e o material didático. Agora repliquem por meio digital, deixem de lado o contato pessoal próximo. Fiquem em casa, no escritório, no aconchego do lar. Não se desloquem, não é mais preciso. Temos as telas, os olhos da grande câmera. Visitem os grandes museus, discutam as obras de arte. É mais seguro sem o contato, sem dispêndio de tempo. Não se prendam entre quatro paredes, abracem-se através das redes sociais virtuais. As telas de led oferecem explorar novos espaços. Não existem barreiras, só os bit e bytes. Sejam criativos, inspiram, é hora de inspirar fundo, e inspirem seus aprendizes. É o mercado do novo milênio. Não tem saída, repliquem isso. Sejam os arautos do século, façam uma nova história, ainda que possam contá-la de outro modo. Agora o convívio se faz nos grandes fóruns on-line de discussão. As dúvidas são dirimidas nas salas de chat. $O$ discurso é on-line. Crie o seu avatar, apresente o seu alter ego. Esse é o espaço virtual, o novo ambiente de aprendizagem, a nova escola. Para que a díade ensinar e aprender aconteça, falta apenas um elemento. Mas, não se preocupem, pois haverá quem nele pense por vocês, professores. Criamos a plataforma de ensino com todos os recursos necessários. Sejam bem-vindos, professores e estudantes, a este admirável mundo novo. As justificativas financeiras pela expansão da EaD estão postas, ainda que as de ordem pedagógica não estejam suficientemente esclarecidas.

\section{REFERÊNCIAS}

ALVES, Nancy Nonato de Lima. Amor à profissão, dedicação e o resto se aprende: significados da docência em educação infantil na ambiguidade entre a vocação e a profissionalização. In: 29ạ. Reunião anual da ANPED. Anais eletrônicos, Caxambú: Anped, 2006.

ARNOSTI, Rebeca Possobom; BENITES, Larissa Cerignoni; SOUZA NETO, Samuel de. Profissão professor: a dimensão afetiva contemplada em sua identidade. Educação: Teoria e Prática: Rio Claro. Vol. 23, n.44. p. 04-23/ Set-Dez. 2013. ISBN: 1981-8106.

BERGERET, Jean. O problema das defesas. In: Bergeret, J. ...[et al.]. Psicopatologia: teoria e clínica. 9 ed. Porto Alegre: Artmed, 2006. 308p

\footnotetext{
14 "Venha aumentar a sua renda, seja um professor!", foi o slogan em uma campanha publicitána de uma das maiores IES privadas brasileiras em número de alunos veiculada no primeiro semestre de 2017, capitaneada por um apresentador global que aparece em muitas telas nas tardes de sábado.
} 
BITTAR, Mariluce. Educação Superior - O "Vale Tudo" na mercantilização do ensino. Quaestio: revista de estudos em educação, [S.I.], v. 4, n. 2, p. p. 51-64, fev. 2013. ISSN 21775796. Disponível em:<http://periodicos.uniso.br/ojs/index.php/quaestio/article/view/1383>. Acesso em: 17 jan. 2017.

BOCK, Ana Mercês Bahia; TEIXEIRA, Maria de Lourdes Trassi; FURTADO, Odair; Psicologia Fácil. São Paulo: Saraiva, 2011. 229p.

BOSI, Antônio de Pádua. A precarização do trabalho docente nas instituições de ensino superior do Brasil nesses últimos 25 anos. Educ. Soc., v. 28, n. 101, p. 1503-1523, 2007.

BRASIL. Decreto 2.494, de 10 de fevereiro de 1998. Regulamenta o art. 80 da LDB (Lei n.․ 9.394/96). Diário Oficial da União, Brasília, 11 de dez. 1998. Disponível em <http://portal.mec.gov.br/seed/arquivos/pdf/tvescola/leis/D2494.pdf>. Acesso em: 24 ago. 2018.

BRASIL. Decreto $n^{\circ} 5.622$, de 19 de dezembro de 2005. Regulamenta o art. 80 da Lei no 9.394, de 20 de dezembro de 1996, que estabelece as diretrizes e bases da educação nacional. Diário Oficial da União, Brasília, 20 dez. 2005. Disponível em <http://www.planalto.gov.br/ccivil_03/_Ato2004-2006/2005/Decreto/D5622.htm>. Acesso em: 22 ago. 2018.

BRASIL. Lei $n^{0} 13.415$, de 16 de fevereiro de 2017. Altera as Leis $n^{0 s} 9.394$, de 20 de dezembro de 1996, que estabelece as Diretrizes e Bases da Educação Nacional, e 11.494, de 20 de junho 2007, que regulamenta o Fundo de Manutenção e Desenvolvimento da Educação Básica e de Valorização dos Profissionais da Educação, a Consolidação das Leis do Trabalho CLT, aprovada pelo Decreto-Lei ํㅡ 5.452, de 1ํ de maio de 1943, e o Decreto-Lei oㅜ 236, de 28 de fevereiro de 1967; revoga a Lei no 11.161, de 5 de agosto de 2005; e institui a Política de Fomento à Implementação de Escolas de Ensino Médio em Tempo Integral. Diário Oficial da União, Brasília, 17 fev. 2017a. Disponível em <http://www2.camara.leg.br/legin/fed/lei/2017/lei13415-16-fevereiro-2017-784336-publicacaooriginal-152003-pl.html>. Acesso em: 22 ago. 2018.

BRASIL. Decreto $n^{\circ}$ 9.235, de 15 de dezembro de 2017. Dispõe sobre o exercício das funções de regulação, supervisão e avaliação das instituições de educação superior e dos cursos superiores de graduação e de pós-graduação no sistema federal de ensino. Diário Oficial da União, Brasília, 18 dez. 2017b. Disponível em <http://www.planalto.gov.br/ccivil_03/_Ato20152018/2017/Decreto/D9235.htm >. Acesso em: 22 ago. 2018.

BRASIL. MEC. Planejando a Próxima Década: conhecendo as 20 Metas do Plano Nacional de Educação. Brasília: MEC/SASE, 2014. Disponível em:<http://pne.mec.gov.br/images/pdf/pne_conhecendo_20_metas.pdf>. Acesso em: 04 jun. 2018.

CORRÊA, Juliane. Formação de professores: o desafio de honrar e dar visibilidade às nossas práticas no ensino superior. Revista CAMINE: Caminhos da Educação, Franca, v. 9, n. 2, 2017.

COSTA, Silvia Generali da. Psicologia aplicada à administração. São Paulo: Elsevier, 2011. 244p.

FALCÃO, Carolina Neumann de Barros; MACEDO, Monica Medeiros Kother. A escuta na psicanálise e a psicanálise da escuta. Psyché, janeiro-junho, ano: 2005. v. IX, n.15. Universidade São Marcos. São Paulo, Brasil, p.65-76. Disponível em: <http://www.redalyc.org/pdf/307/30715905.pdf>. Acesso em: 15 jan. 2018.

FENICHEL, Otto. Teoria Psicanalítica das Neuroses. São Paulo: Editora Atheneu, 2005.

FOCHESATTO, Waleska Pessato Farenzena. A cura pela fala. In Estudos de Psicanálise. Belo Horizonte - MG. n. 36. p. 165-172. Dezembro, 2011.

FREIRE, Paulo. Pedagogia da autonomia: saberes necessários à prática educativa. SP: Paz e Terra, 1996.

FREUD, Ana. O Ego e os mecanismos de defesa. 4 ed. Rio de Janeiro: Editora Civilização Brasileira, 1977, $149 \mathrm{p}$. 
FREUD, Sigmund (1911-1913). O caso Schreber, artigos sobre técnica e outros trabalhos. - O tema dos três escrínios (1913)- Edição Standard Brasileira das Obras Psicológicas Completas. v.XII. Rio de Janeiro: Imago, 1996.

FREUD, Sigmund (1916-1917a). Conferências Introdutórias de Psicanálise, Conferência parte III- XXI - O desenvolvimento da libido e as organizações sexuais. Edição Standard Brasileira das Obras Psicológicas Completas. v.XVI. Rio de Janeiro: Imago, 1996.

FREUD, Sigmund (1916-1917b). Conferências Introdutórias sobre Psicanálise (Parte III) Teoria geral das neuroses (1917 [1916-17]) - Conferência XXII: Algumas idéias sobre desenvolvimento e regressão - Etiologia. - Edição Standard Brasileira das Obras Psicológicas Completas. v.XVI. Rio de Janeiro: Imago, 1996.

FREUD, Sigmund (1925-1926). Além do princípio de prazer, psicologia de grupo e outros trabalhos. Psicologia de grupo e a análise do ego (1921). Cap. VII - Identificação - Edição Standard Brasileira das Obras Psicológicas Completas. v. XVIII. Rio de Janeiro: Imago, 1996.

FREUD, Sigmund (1893-1899). Primeiras publicações psicanalíticas. O mecanismo psíquico do esquecimento (1898). Edição Standard Brasileira das Obras Psicológicas Completas. Vol.XVI. Rio de Janeiro: Imago, 1996.

FRIGOTTO, Gaudêncio. Trabalho. In: OLIVEIRA, Dalila Andrade; DUARTE, Adriana Cancella; VIEIRA, Lívia Fraga. Dicionário: trabalho, profissão e condição docente. Belo Horizonte: Grupo de Estudos sobre Política Educacional e Trabalho Docente (GESTRADO-UFMG), 2010. Disponível em: <http://www.gestrado.org/?pg=dicionario-apresentacao>. Acesso em: $30 \mathrm{abr}$. 2018.

GIL, Antonio Carlos. Como elaborar projetos de pesquisa. 4. ed. São Paulo: Atlas, 2008. 175 p.

GODELIER, Maurice. Trabalho. In: GIL, Fernando, coord. Modo de produção, desenvolvimento e subdesenvolvimento. Enciclopédia Einaudi. Lisboa: Imprensa Nacional/Casa da Moeda, 1986. v. 7. p. 11-12.

GOLDOI, Christiane Kleinübing; BALSINI, Cristina Pereira Velchio. A pesquisa qualitativa nos estudos organizacionais brasileiros: uma análise bibliométrica. In: Pesquisa qualitativa em estudos organizacionais: paradigmas, estratégias e métodos. São Paulo: Saraiva, 2006.

HUFFMAN, Karen; VERNOY, Mark; VERNOY, Judith. Psicologia. São Paulo, Atlas, 2003. $814 p$.

INSTITUTO NACIONAL DE ESTUDOS E PESQUISAS EDUCACIONAIS ANÍSIO TEIXEIRA. Sinopse Estatística da Educação Superior 2016. Brasília: INEP, 2017. Disponível em: $<$ http://portal.inep.gov.br/web/guest/sinopses-estatisticas-da-educacao-superior>. Acesso em: 26 fev. 2018.

LAPLANCHE, Jean; PONTALIS Jean Bertrand. Vocabulário de psicanálise. 9 ed. São Paulo: Martins Fontes Editora Ltda, 1986, 707 p.

LESSA, Shara Christina Ferreira. Os reflexos da legislação de educação a distância no Brasil. Revista Brasileira de Aprendizagem Aberta e a Distância - ABED, v. 10, 2011, p. 17 28.

MARCONI, Marina de Andrade; LAKATOS, Eva Maria. Fundamentos de Metodologia Científica. 7.ed. São Paulo: Atlas, 2016. 297p.

MARINHO, Simão Pedro Pinto; REZENDE, Paula Andréa de Oliveira e Silva. Disciplinas virtuais nos cursos de graduação, a busca por uma sustentabilidade pedagógica. Educação \& Linguagem, v. 17, n. 2, p. 17-37, jul.- dez. 2014

MARX, Karl. $O$ capital: crítica da economia política. Série: Os Economistas. v. I. Livro Primeiro In O processo de produção do capital - Tomo 1. São Paulo: Editora Nova Cultural Ltda. 1996, 496p.

MARX, Karl. O pensamento vivo de Marx. 8.ed. São Paulo: Martin Claret Editores. 1985. 109p. 
MILL, Daniel Ribeiro; SANTIAGO, F. Carla; VIANA, Inajara de Salles. Trabalho docente na Educação a Distância: condições de trabalho e implicações trabalhistas. Revista extra-classe, Belo Horizonte, v. 1, n. 1, p. 56-73, fev. 2008.

MONTEIRO, Agostinho dos Reis. Profissão docente: Profissionalidade e Autorregulação. São Paulo: Cortez, 2015, 318p.

MUGNOL. Marcio. A educação a distância no Brasil: conceitos e fundamentos. Rev. Diálogo Educ., Curitiba, v. 9, n. 27, p. 335-349, maio/ago. 2009.

NEVES, Inajara de Salles Viana; FIDALGO, Fernando Selmar Rocha. Docente virtual na Educação a Distância: condições de trabalho na rede privada de ensino, 2008. Disponível em:<http://www.senept.cefetmg.br/galerias/Arquivos_senept/anais/quarta_tema3/Quarta Tema3Artigo7.pdf>. Acesso em: 23 abr. 2017.

PETERS, Oto. Didática do ensino a distância. São Leopoldo: UNISINOS, 2006.

RAMOS-DE-OLIVEIRA, Newton. Reflexões sobre a educação danificada. In: A educação danificada: Contribuições à Teoria Crítica da Educação. Petrópolis: Vozes/São Carlos: UFSCar, 1998.

ROSSO, Brent D.; DEKAS, Kathryn H., WRZESNIEWSKI, Amy. A theoretical integration and review. Research in Organizacional Behavior, pp 91-127. 2010. Disponível em: <http: www.sciencedirect.com>. Acesso em: 21 abr. 2017.

SOUSA, Adriana Modesto de. O perfil do adoecimento docente na Universidade de Brasília de 2006 a 2011. Dissertação (Mestrado em Ciências da Saúde) - Programa de Pós-Graduação em Ciências da Saúde da Universidade de Brasília, Distrito Federal, Brasil, 2013. 113p.

STAKE, Robert E. Multiple Case Study Analysis. New York, New York: The Guilford Press, 2006.

TARDIF, Maurice; LESSARD, Claude. 0 trabalho docente: elementos para uma teoria da docência como profissão de interações humanas. 9. ed. Petrópolis: Vozes, 2005. 320p.

VEIGA, IIma Passos Alencastro; D’ÁVILA, Cristina Maria. (Orgs.). Profissão Docente: Novos sentidos, novas perspectivas. 2.ed. Campinas, SP: Papirus, 2012. 176p.

VERGARA, Sylvia Constant. Projetos e Relatórios de Pesquisa em administração. 15.ed. São Paulo: Atlas, 2014. 94p.

VIGANÒ, Carlo. A construção do caso clínico em saúde mental. Revista Curinga. EBP - MG, n.13, p.39-48, set, 1999.

YIN, Robert K. Estudo de Caso: planejamento e métodos. 3. ed. Porto Alegre: Bookman, 2005. $212 \mathrm{p}$.

Data da submissão: 05/12/2018

Data da aprovação: 21/02/2019 